\title{
COMPARISON OF PROJECT PLANNING \& SCHEDULING SOFTWARE'S PRIMAVERA AND MICROSOFT PROJECT USED IN THE CONSTRUCTION INDUSTRY
}

\author{
Sudarshan. S $1 \square$, Geena George ${ }^{2}$ \\ ${ }^{1}$ PG student, Department of Civil Engineering, EPCET Bangalore, India \\ ${ }^{2}$ Associate Professor, Department of Civil Engineering, EPCET Bangalore, India
}



Received 22 August 2021

Accepted 01 September 2021

Published 30 September 2021

\section{CorrespondingAuthor}

Sudarshan. S, 1981.sudarshan@gmail.com DOI 10.29121/ijetmr.v8.i9.2021.1039

Funding: This research received no specific grant from any funding agency in the public, commercial, or not-for-profit sectors.

Copyright: (C) 2021 The Author(s). This is an open access article distributed under the terms of the Creative Commons Attribution License, which permits unrestricted use, distribution, and reproduction in any medium, provided the original author and source are credited.

\section{ABSTRACT}

Planning and scheduling is extremely important role in construction projects thank to the increasing difficulties during this field. Construction Planning is that the necessary warning to Scheduling and determining general sequence, defining labour tasks, construction methods and assigning responsibilities, inappropriate planning can cause major delays with the project work.. For planning and scheduling work requires huge amount of paperwork, which makes the management very burdensome. In this research two software's used which describes about the project as per the software working. Purpose of MSp \& P6 is to analysis the project to know the completion dates. During this analysis of software's procedure for project starting dates of the projects and baselines are fixed, based on work flow predecessors are fixed and final dates area approached. As the option of calendar's are more in P6 it gives precise calculation These problems may be solved employing a project management software which helps to grant a planned approach to planning. Nowadays use of project management (PM) software as a tool for managing and organizing work has gained its importance in construction industry and continues to grow at a faster pace in other industries also. During this study, attempt is made to check project management software such as MS project and due to the more precise calculation Primavera p6 gives good results as compare to Msp. One of the WSB is considered in both the software's small analysis is done and final dates of activity and their feasibility is studied.

Motivation/Background: Importance of this analysis is to understand about the p6 software and schedules, methodologies to be adapted properly to get the precise project dates.

Method: As the option of different calendar's in p6 it will analyse the project precisely and gives the project dates.

Results: P6 will study or analysis entire project dates with comparison of Msp in excel and in Msp project dates are optimized with some \% of reduction in WBS and parallel activities dates has been optimized. This study gives the results as P6 will be precise in any of the projects and planning activities.

Conclusion: Both the software's Msp and Primavera P6 has it uniqueness, and this study says for a good results in the project P6 will give a good results in the project scheduling.

Keywords: Primavera P6, MS Project, CPM,EPS, Construction 


\section{INTRODUTION}

Project Management is the application of information, capacities and Techniques to stretch outs to encounter task prerequisites. An essential capacity to achieve somewhat efficiently for relations. It is very well be characterized as the cycle and movement of preparation, positioning, rousing and controlling assets. Strategies and conventions to accomplish clear objectives. The task is relied upon to get finished inside the predefined time cut-off and spending plan. There are various programming's accessible in $t$ for project the board. MS task and Primavera are generally utilized for arranging and booking. Arranging of gigantic ventures requires colossal measure of administrative work, which is decreased with the assistance of P6 and MS project programming. Every product has got its own benefits and negative marks. These apparatuses help us for streamlining the development technique to forestall time and cost to finish the task in arranging span and inside the financial plan. It is planned in such a manner to assist with extending supervisors in making an undertaking plan, allocating assets to task things, keeping tabs on their development, refreshing of venture, allocating by spending plan, and separating responsibilities.

According to T. Subramani (2015)[T. Subramani et al.(2014)] Primavera P6 is a software is not only used by project planners but also involved in project, i.e. managers, engineers, schedulers. Primavera software focusing on the advantages and comparison of construction estimate methods application in usefulness project. P6 allows users to generate project templets, which can used for future project also. Primavera can also be used to group and view multiple project at the same time.

The resource plays important role in any construction project. It performance of any construction project directly depends upon resource management. The resource optimization and levelling using primavera P6 software about 5.65\% resource reduction is observed [ Reddy (2015)]. When compares MSP \& primavera, open workbench for resource levelling in two real time project and the result shows primavera gives most the critically unlimited number of criteria as priority rules. The process and activity of planning, organizing exciting and controlling resources, procedures, to achieve complete goals in scientific or daily problems that help to overcome the problems. It helps for the optimum and effective organization of activities to complete the project in planned duration and within the market.[Castor (2008)]

The time performance of the conventional method of construction for high- rise residential and commercial projects method by originate level measures of industry norms for overall construction period using scheduling simulation modelling. The positive changes include creating a healthy working environment among those involved directly in the construction industry. Improved Customer satisfaction whenever you get a project done on time and under budget. It helps easily plan and manage project activities, optimizes management of all resources and gives clear visibility of project allows quick and easy forecasting of WBS's, activities or projects. [Ragavi and Uma (2016), Subramani (2018)].The improper resource management results in huge amount wastage, also causes increase in time duration. Using Primavera software, we can organize project properly and recognize potential problems. Primavera software is used for making project management easier, especially in difficulties [Umesh (2015)].

Projects are regularly exploited as a method of directly or indirectly achieving points within an organization's strategic plan. Projects are typically authorized as results of one or more of the subsequent strategic considerations. Planning involves 
deciding in prior to what's to be done, how and in what order it is to be done in order to achieve the objectives. Planning aims at deciding upon the long run course of action. In brief, Planning and scheduling involves a) Collecting and synthesizing information. b) Developing alternative courses of action within specified constraints. c)Comparing alternatives in terms of objectives feasibility and consequences. d) Selecting and scheduling the optimum course of action. e) Establishing policies, procedures, methods, schedules, programs, systems, standards and budgets for accomplishing project objectives.

\subsection{PLANNING AND MANAGEMENT}

Project management is that the application of knowledge, skills, tools, and techniques to project activities to satisfy the project requirements. Project management is proficient through the acceptable application and integration of the 47 logically grouped project management processes, which are categorized into five Process Groups. a) Initiating b) Planning c) Executing d) Monitoring, Controlling and e) Closing. In project planning sequencing of the work will work more as compare to unplanned project. The following are the step by step procedure for project planning. a) Make a detailed list of activities b) Prepare a network diagram c) Identify the critical path d) Allocate the resources or juggle the schedule

The mail objective of the project mission is unique and it is based on different sits and locations. In this project, it has been comparison between two software's for calculation the project completion days. Entire project schedules with different break down structures is compared with other software and procedures adopted. It is difficult to monitor the project from corporate which makes a challenge in coordination with the site management and the management team. Project execution involves working in dangerous condition (heights, depths etc) which may have the chances of more accidents as compared to other industries. Project functioning under higher peril and uncertainty when associated with construction practices as the lack of time flexibility is due to completion of the project. As the delays during the execution can impacts the subsequent activities work schedule and which may results in paying high penalties from the vendors or from the client to the vendors.

Project not only depends on the timelines but also the quality of the work is also most important in any project and different commercial, residential, infrastructure projects has standards which is to be followed and maintained throughout the project. In case of any defects entire exaggerated work may get rejected or the partial work. Either has impact on the time cost, timeline of the projects and which may demotivate the project team. If the quality is not maintained properly and regular interval inspection is not done during the execution which will be further impact in the operations of any projects and handing over or closeout of the project.

\section{RESEARCH METHODOLOGY}

A project life cycle could be a collection of generally sequential and sometimes overlapping project phases whose name and number are determined by the management and control needs of the organization or organizations involved within the project, the nature of the project itself, and its area of application. The life cycle provides the essential framework for managing the project, regardless

of the specific work involved. Irrespective of how large or small, simple or 
complex, all projects can be mapped to the following life cycle structure. a) Starting the project b) Organizing and preparing c) Carrying out the project work, and d) Documenting and handover of project \& closeout. This generic life cycle structure is commonly observed when communicating with upper management or other entities less at home with the main points of the project [Dubey (2015)]. This high -level view can provide a common frame of reference for comparing projects-even if they are dissimilar in nature.

Function of project management are different as compared to different projects but as summarized five basic functions of project management is followed in all project execution for smoothly completion of project. a) Planning b) Organizing c) Staffing and provisioning resources d) Directing or leading e) Controlling. There must be an categorical operational plan to guide the entire project. The plan must include and link the three components of the project: scope, budget and schedule. Too often, planning is focused only on schedule without regard to the important components of budget and scope. This process starts with WBS. Planning, scheduling and controlling begin at the inception of the project and continue till the life of the project until completion. In this study a hotel project is considered and planning and scheduling using software's MSP and Primavera is used and comparative study is conducted.

\subsection{MICROSOFT PROJECT (MSP)}

Project management wares, software product, introduced \& developed by Microsoft. It assist a project manager in developing a planning, assigning resources to tasks, tracking progress, managing the budget, and analysing workloads. Project creates budgets assignment work and resource rates. Resources are assigned to tasks and work is estimated. Program calculates the cost, suitable to the work times the rates. Resource defines (people, equipment and materials) may be shared between projects employing a shared resource pool. Each resource can have its own calendar, which defines days and shifts a resource is available. Resource rates are used to calculate resource assignment costs which are revolved up and summarized at the resource level. Each resource can be a signed to multiple tasks in multiple plans and every task can be assigned multiple resources. Schedules task work based on the resource availability as defined in the resource calendars. All resources may be defined in label without limit. MSP unsuitable for solving problems of available materials. Calendars option are less as compare to primavera software and due to which outcomes of the schedules may vary and changes entire project dates.

\subsection{PRIMAVERA P6}

Primavera was launched in 1983 by Primavera Systems which was acquired by Oracle Corporation in 2008. Primavera is an enterprise project portfolio management software. It includes project management, scheduling, risk analysis, opportunity management, resource management, control capabilities, and integrates with other enterprise software such as Oracle and SAP's ERP systems[ Subramani et al. (2017), Veena and Vijay (2016)]. This software is designed for project, program, and portfolio management. It is a powerful, easy to use solution for planning, managing and executing projects. Primavera incorporates a huge performance and easily can't be beat. Installing local software on PC cut's out the lag of web-based products and screen refreshes. It makes P6 professional tool for 
scheduling projects. Calenderers options are more in the software which is very precise in outcome of schedules.

\subsection{COMPARISON BETWEEN MSP AND PRIMAVERA SOFTWARE}

Each software's has its own uniqueness in calculating the projects timelines and it has different baselines, calendar's in resources, costing, etc. and some several users also works on a single project with specific features. In MSP project can be can be stored in the disk for future reference and also stored in the servers. It allows creation of different activities under different WBS and with different Id's which allows creating of proper costing, expenses etc. Primavera P6 is one of the planning software which provides the details entirely about the about the project at micro level as it has auto levelling of resources schedules dates are calculated.

As compared to MSP, Primavera has more baselines creations based on project requirement. It doesn't allow the multiple workers using of single project and has restriction because of safety of project document as multiple user may mislead the project scheduling, costing etc. In this software activity cannot be created when and where it is required as it has to follow the WBS and create activities. As it supports exclusive ID article and the activity ID is reliant on the location of the activity. Activity can be controlled as individual activities and which can be moved from their positions to where it to display. It is best suited in developing countries as software is costlier as compare to MSP.
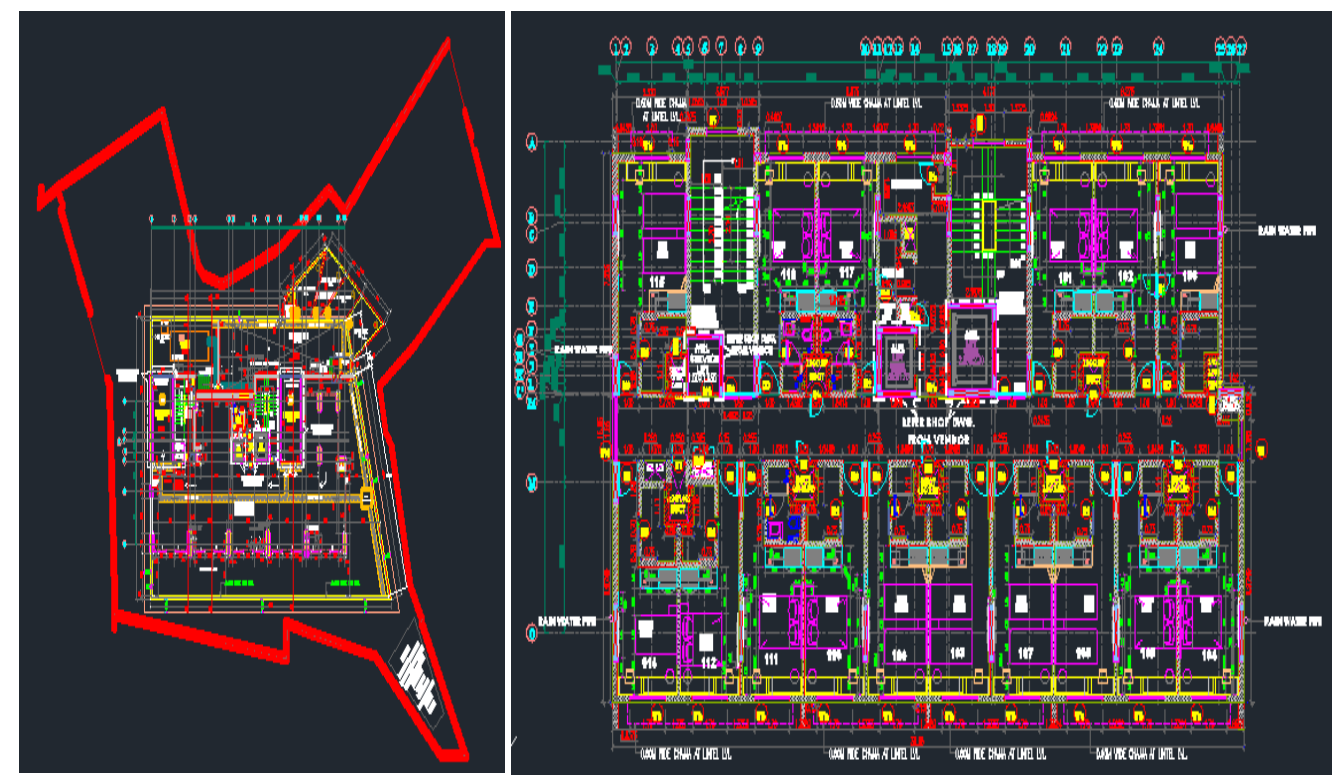

Figure 1 Plan of Hotel building considered for the study

\section{RESULTS AND DISCUSSION}

A hotel building with $\mathrm{B} 2+\mathrm{G}+11$ storey building was considered for the study. Planning and scheduling is done with MSP and Primavera and detail analysis is conducted. Results of the analysis says 120 days was extra needed to complete the project in Msp as compared to P6. 


\subsection{DATA ANALYSIS USING MSP}

By Msp entire scheduling with baseline calendars is done with different activities precisely to know the number of days required to complete the project. Each WBS has different days and total project days has been calculated with the maximum/critical activity days of the activates considered. As the hotel project required the mock-ups for the guestrooms and approval from the management and different consultants for the civil structural, MEP, Interiors, landscape and hardscape of the project. As these required précises calculation so that project is completed without hindrances. After calculating the project days it has been compared with Primavera P6 for more information about the scheduling, Resources, costing. MSP calculation found more project days as compared to P6. By optimization and analysis of the p6 software days and WBS dates are calculated and reduced by $5 \%, 6 \%$ and finally by $8 \%$ project timelines of the both software were matched.

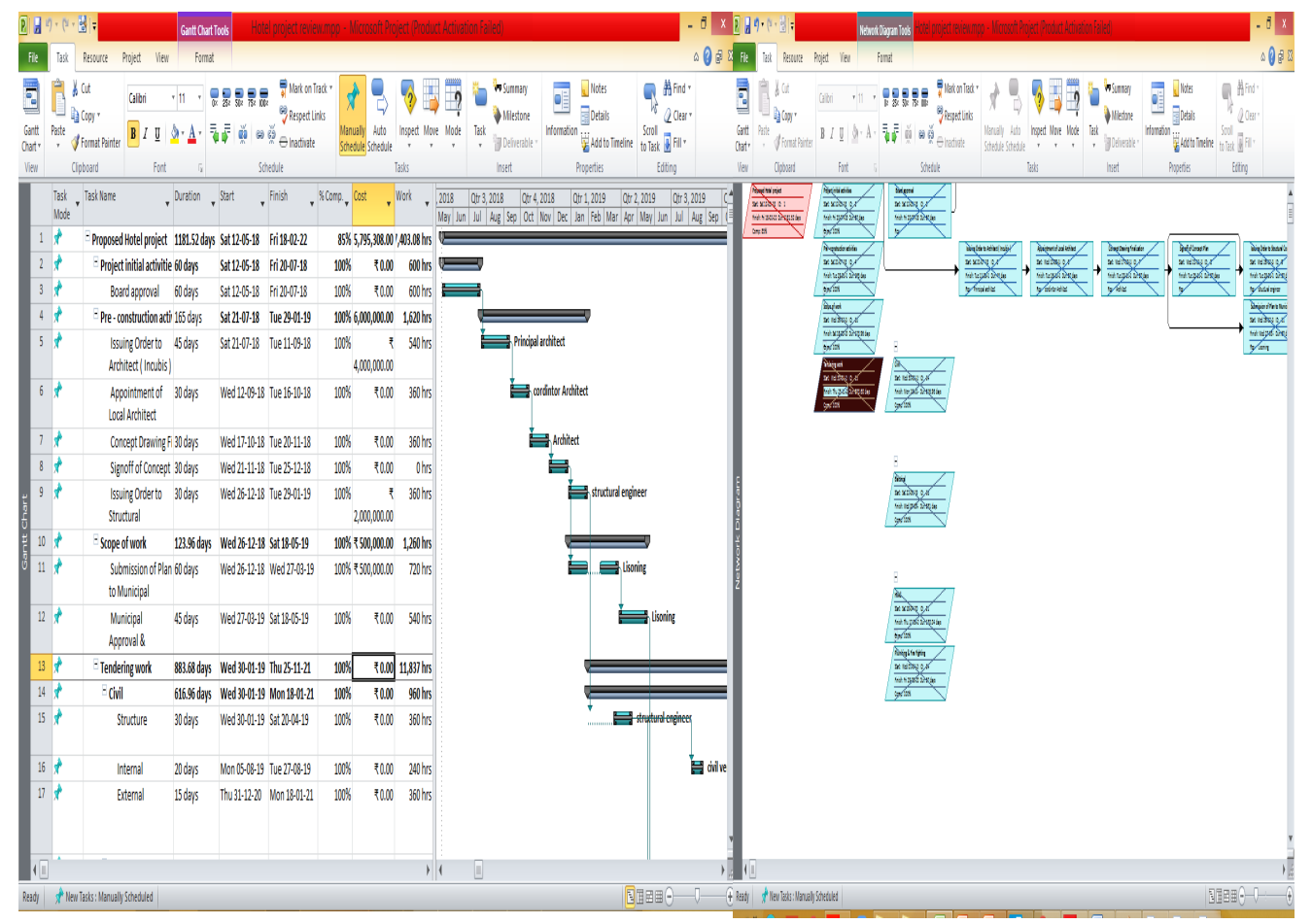

Figure 2 Data Analysis using MSP

\subsection{DATA ANALYSIS USING PRIMAVERA}

In Primavera p6 also calendar's to be set has different calendars setting by which different WBS can be set and analysis of design in the way such that Entire WBS to be created first, below each WBS activity to be created. As the predecessors are given optimized date is calculated by the use of the calendar opted. Project final dates are reflected.

Once the final dates of the activity schedule, resources schedule is done, it is analysed along with comparison with MSp for the optimization results. As Primavera is designed in better way it give précises dates, in this project analysis I have got 4 months early closer of the project as compared to Msp.Changes main 
occurred due to the different calendars option in the P6 which will help to know the exact dates which is required in the project.

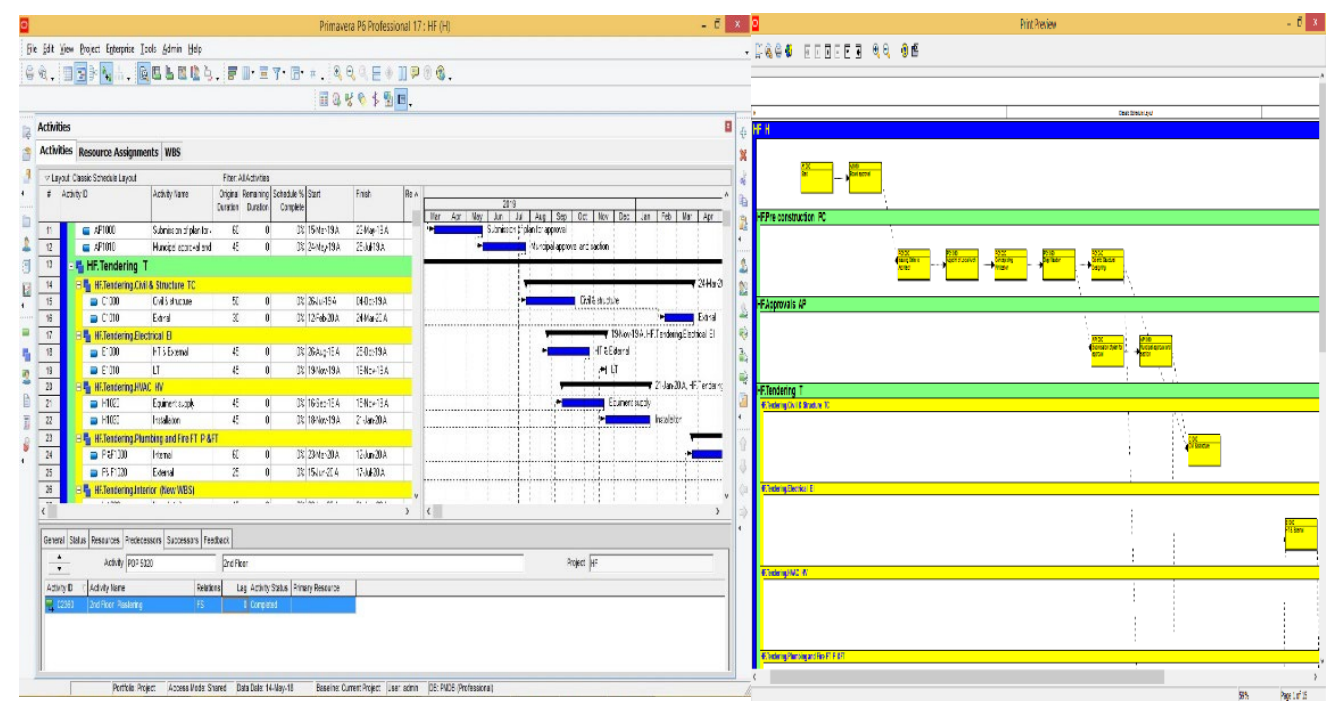

Figure 3 Data Analysis using Primavera

\subsection{DATA ANALYSIS BETWEEN PRIMAVERA \& MSP}

When examination on P6 is done, It was spotted planning and scheduling, time duration of the building completion was reduced by nearly 3 months in P6. Henceforth later cautious study this methodology we can govern the project in terms of interval hence leading to time \& cost optimization. Entire scheduling

Comparison is made with the excel and detailed output is attached in the Excel as in fig 4. The difference in the both the software's is mainly due calendars of the software's .Calendar in P6 is having more precise and having difference option so that it can be adopted to be activities. Calendars in MSP having some restricted option to adopt in assign to the activities. Optimization of the schedules are done in the MSP by reducing the float. When entire project was calculated difference of 3 months was noticed

Dates are optimized on major activities considered and dates are reduced by $5 \%, 7 \%$ and at $8 \%$ dates are matched with the P6. Example of Window supply and installation is considered. Activity starting dates and closing dates area same in the both the software's area scheduled. Difference b/w the both software's are calculated and difference of both the software's are recorded. In MSP activity starting date is 14.10 .20 and entire activity is ending on 22.04.21. In P6 activity starting date is 14.10.20 and entire activity is ending on 01.04.21. So the difference b/w MSP and P6 is 22days was recorded. Based on different work activities difference was recorded and optimized in the later stages of the project tracking. 




Figure 4 Data analysis between Primavera \& MSP

Every project is unique. The methodology to maintain men and material are well understood through the knowledge of construction process as two projects are alike. Comparison done b/w MSP \& P6 total difference of time to complete project in p6 \& MSP is of about 4 months. As it saves the total price of the project and the overheads. The project control software tools helps in accomplishing the task in stipulated time. The results of earned value analysis show that the project cost is reduced as project completes as planned to avoid unforeseen increase in labour and material cost.

\section{CONCLUSION}

Planning of scheduling is done in this study to understand the efficiency of two different software's Primavera P6 and MSP in construction projects. Planning, scheduling, tracking of project is completed proficiently by Primavera P6 software. Several projects of organization may be disbursed proficiently by using Primavera P6 software. In research it is acknowledged that P6 software is valuable in resource flattening and resource leveling procedure. Primavera P6 software is more effective, reduced period intense and it needs less administration than conservative method. In this research it has provided detail information about, time management, working hour administration. Monitoring of activities which enhance success in conveying services.

In Primavera p6 different calenderers are assigned for Pre execution activities and execution activities. Primavera helps in find out critical movements of plan so that different apprehension will be those actions which delay in the project are often avoided. Reduction of $5 \%$ to $8 \%$ in the labour cost 
may be attained using Primavera P6 as it gives precise scheduling. The methodology to keep up men and material are well understood through the knowledge of construction process. Primavera \& MSP both the software's has their own unique process in scheduling the activities. The project management software tools helps in accomplishing the task in stipulated time. The important milestones or deliverables are identified using the CPM.

The results of earned value analysis show that the project cost is escalated because of unforeseen increase in labour and material cost. The extra cost that has incurred can be recovered within the next activities in the line by adopting the project controlling tools like fast tracking and activity duration crashing. The duration of the remaining activities is reduced by using project management techniques and rescheduling the project. Float activities to be taken care altogether the planning activities so that work activities in order that are completed in time. In the analysis we need to know primavera is more precise and schedules dates are reduced compared to MSP

\subsection{RECOMMENDATIONS}

In light of the research findings, the following recommendations were made to improve the influence of Project on project scheduling performance. There should be continuous training and evaluation of project in private and public firms. This would ensure that the project schedule has adequate technical skills require for their activities and effective of project. Project should also improve on their communication skills for adequate and effectiveness communication. Improve on inspections of project.

\section{ACKNOWLEDGEMENTS}

I hereby acknowledge with thanks East Point College of Engineering \& Technology for helping me in this this research publication of our paper in your journal. I extend my deep of sincere gratitude to Dr. T.K. SATEESH Principal,for providing support for all Project related activities. Also express my heartfelt sincere gratitude to Dr.NAGARAJ SITARAM HOD of Civil Engineering, for his valuable suggestion and support. I extend sincere gratitude to my project co-ordinator and guide Mrs. GEENA GEORGE, Assistant Professor, Department of Civil Engineering, for her entire support, guidance, suggestion given throughout the development of project.

\section{REFERENCES}

A. Castor (2008) "Review of Project Management Softwares - MS Project \& Primavera"

Anuj Dubey (2015) "Resource Levelling for a Construction Project", IOSR Journal of Mechanical and Civil Engineering (IOSRJMCE) e- ISSN: 2278-1684, p-ISSN: 2320-334X, Volume 12, Issue 4 Ver. IV (Jul. - Aug. 2015).

B.S.K Reddy (2015) A study on optimisation of resources for multiple projects by using primavera", Journal of Engineering Science and Technology 10(2):235-248.Retrieved

from

https://jestec.taylors.edu.my/Vol\%2010\%20issue\%202\%20February\%20 2015/Volume\%20(10)\%20Issue\%20(2)\%20235-248.pdf 
Nikhil R. Mahajan, Vaishali Joshi (2017) "Resource Scheduling in Construction Project Using MSP" International Journal of Innovative Research in Science, Engineering and Technology, Vol. 6, Issue 1, January 2017

S. Ragavi, R. N.Uma (2016), "Review of Project Management Softwares- Ms Project And Primavera" International Research Journal of Engineering and Technology (IRJET), Volume: 03 Issue: 11 |,Nov -2016 Retrieved from https://d1wqtxts1xzle7.cloudfront.net/54340814/IRJET-V3I11236-withcover-page-v2.pdf?Expires $=1633592582 \&$ Signature $=\mathrm{e} 1-$

YDz1diOmIU03rhXYcGHQsW46vuS9auSBleEwN8tqtywPUe1Nix3t9C61ZM YDNl2gAm75ZZDsewCaDk3AJCxhz9B-

VXHr2UOKA1ymqt2Z0Yx S0UDBrdUqtm6vNamHiEmOh38WH3GIzHgECc iJHfJwhZa lPV3XWE7qr7rTqn0yLoG0yWt92gR9PEsn4rklYzgyr0MRVffaQ E0uiHTVYUGkqeBDSzvk-

XyBJ6ubUxnob8ln7Q0bm2j sp3lf98LUpMTzOv7D F4LbShHBkonQiAgN3 nHb12igbn-Tx4GRKw7s2rfSC3IJ6GbPe1AGEp-

EY5nEQMuv1ZmTaGAYcrQ_\&Key-Pair-Id=APKAJLOHF5GGSLRBV4ZA

T. Subramani (2018), "Study on Time and Resource Management in Construction Projects Using MS Project" International Journal of Engineering \& Technology 7(3.10):23 Retrieved from https://doi.org/10.14419/ijet.v7i3.10.15622

T. Subramani , A. Sarkunam , J. Jayalakshmi (2014) "Planning and Scheduling of High Rise Building using Primavera" ISSN: 2248-9622, Vol. 4, Issue 6 (version 5), June, $\quad$ pp. 134-144. Retrieved from https://core.ac.uk/download/pdf/26887782.pdf

T. Subramani, V. Annamalai, S. Priyanka, (2017) " Management Information And Communication Technology In Construction Engineering Of Structures Using Primavera ", International Journal of Emerging Trends \& Technology in Computer Science (IJETTCS), Volume 6, Issue 3, May - June, pp. 186-197, ISSN 2278-6856.

Veena H C, Vijay K (2016) "Schedule Control of an Apartment Building using Primavera Techniques" ISSN: 2278-0181, Vol. 5 Issue 06, June-2016 Retrieved from https://doi.org/10.17577/IJERTV5IS060822

Y. Umesh (2015) Review of Project Management Softwares MS Project \& Primavera Planning, Scheduling and Tracking of a residential Project using Primavera Software, International Journal of Advance Research in Computer Science and Management Studies, Volume 3, Issue 5, May 2015 Retrieved from https://d1wqtxts1xzle7.cloudfront.net/47211378/B012440511.pdf?1468 407802=\&response-content -

disposition=inline\%3B+filename\%3DResource_Levelling_for_a_Constructi on_Pr.pdf\&Expires=1633592652\&Signature=FRnZM2T0Y8CbRpzMPHh3k Tg7vFewe6VGYZShQT79d8X7aFfM8yos3sJXENKIGsbMN2xExWrAACTyvU cRbymR7fWne5MisV-sWFpGcaFJCu5 BT uMZcAAiyerqlUq8twGrXEWzlPQv2cU4 wBd3wGEyFhPfAavcDu zUejljVhRyqE72qt SizYPZ5MNOgFmm yGDxOtZ7SWwUiiC9gEEgNitKYx0q2RD8mY1nPu Z mSSwFrekaC6A8h5b-8zdZkSHK0RfgVeEsBNvTiU01A FE-PwjYH8vIXY7uYIzrGpLyspEfsXHO3accOkHNNCXzpVnHNIwuoSsm330S4NA_\&Key-PairId=APKAJLOHF5GGSLRBV4ZA 